International Journal of Linguistics, Literature and Translation (IJLLT)

ISSN: 2617-0299 (Online); ISSN: 2708-0099 (Print)

DOI: $10.32996 / \mathrm{jjllt}$

Journal Homepage: www.al-kindipublisher.com/index.php/ijllt

\title{
Digital Inequity Survey to the Teachers of St. Aloysius Academy of Dasmariñas: A Basis for Digital Trust and Intuition
}

Dr. Crisanto E. Avila

Master of Development Communication, University of the Philippines Open University, Philippines

Corresponding Author: Dr. Crisanto E. Avila, E-mail: john_xryz@yahoo.com

ARTICLE INFORMATION

Received: November 08, 2020

Accepted: December 17, 2020

Volume: 3

Issue: 12

DOI: 10.32996/ijltt.2020.3.12.26

\section{KEYWORDS}

Digital Inequalities, Digital

Learning Tools, Digital Trust,

Digital Intuition, Digitalization

\section{ABSTRACT}

In the field of education, teachers must be technologically abreast especially in time of the COVID-19 Pandemic addressing the demand of the New Normal. To build confidence and capacity in digital teaching-learning, teachers must consider developing their skills in using digital technologies in education and they must also embed the use of digital devices in the teaching-learning practice. In this premise, this research article explains the digital inequality that the teachers are experiencing and its effect on their teaching profession and on establishing among themselves the digital trust and intuition. This study also aimed to answer, "What are the digital equalities do teachers encounter?" Th teachers' decision for digital trust and intuition is affected by the digital inequalities they are experiencing. This study draws insights from a one-page survey questionnaire to 20 selected teachers of St. Aloysius Academy of Dasmariñas representing the faculty from the 3 departments such as preschool, grade school and high school. The results of this study indicate that teachers of St. Aloysius Academy of Dasmariñas are digitally inclined as manifested by their subscriptions to various digital devices and services. The impact of the digital technology to them in terms of social, economic, political and cultural affects their decision in digital trust and intuition. Overcoming issues on digital inequality among teachers will lead to digital trust and intuition. The school, from where the teachers are employed must address the digital inequality by ensuring that all teachers have equal chances in accessing the technology-based teaching devices and by providing them capacity building trainings which are imperative for the demand of the new normal. Teachers must embrace the digital technology in the community and in their workplace and imbibe the digital trust and intuition in education.

\section{Introduction}

With the challenges brought by COVID-19 Pandemic, digital technology is very instrumental in avoiding the spread of the virus and making the peoples' activities possible to the standard of the new normal. As part of the Science and Technology aspects of human lives on earth, digital technology has transformed modern life, bringing life comfort and many advantages. (quora.com)

Goodman (2020) emphasized that digital devices revolutionized every aspect of modern life in travel, work, shopping, entertainment and communication. Almost all electronic devices have been digitized, incorporating digital technology.

Further, Goodman explained that in digital technology, devices can be more compact, faster, lighter, and more versatile which has the capacity to store big amounts of information locally or remotely and moved around virtually instantaneously. Information expanded its scope and now includes other media such as photos, audio, and video, and no longer refers to just words and numbers.

K C AL-KINDI CENTER
$\mathbf{R}$ D FOR RESEARCH AND
Your gateway to world-closs reiearch
Published by Al-KindiCenter for Research and Development. Copyright (c) the author(s). This is an open access article under CC BY license (https://creativecommons.org/licenses/by/4.0/) 
Digital devices are products of advanced technology. In all fields today, technology plays a key role in the process and its development. Technology dictates the parameter of development in every field. For whatever development each one to take, all are anchored on technological advancement.

In the field of education, teachers use digital technology-based learning devices. It happens across all curriculum learning areas especially in time of the pandemic ensuring the implementation of the School Learning Continuity Plan under the new normal. However, it is just normal that we don't have equal opportunities of enjoying the benefits of digital devices because of social inequality, the uneven distribution of opportunity, and the chances of other factors. It is enviable to every individual, accept it or not. Teachers' decision for digital trust and intuition is affected by the digital inequalities they are experiencing.

Teachers must be technologically abreast. To build their confidence and full capacities in digital learning, teachers must consider developing their skills in using digital technology based learning devices and they must embed the use of these modern learning devices in their teaching practice.

In the business world, Slaymaker (2020) argued that traditional approaches in the business of creating a reputation for trustworthiness through branding, advertising and physical presence are shifting to the trustworthiness customers perceive as they experience millions of digital interactions across their entire customer journey.

While in digital trust in education, Lee (2016) advocated for the use of digital technology in teaching. He believed that the ICT experts and the school personnel that includes principals must collaborate for digital evolution of the schools.

Lee in his paper said that in schools, the students have to use the prescribed device, the specified software, and have every keystroke monitored. Students cannot be trusted with their own digital technologies within the classroom without a teacher supervising. This is one issue of digital mistrust in the schools that has to be overcome.

For digital intuition, Waks (2006) explains that the rich experience of teachers may guide them for their decision of taking opportunities to answer present challenges in the way that they decide without delay and maintain to generate educational value. When teachers are free from stresses and inevitable difficulties in their workplace, their work can exhibit intuition.

However, it is sad to note that due to the mediocre salary of teachers and budget in schools, they became victims of digital inequalities that their capacities as teachers are affected and the quality of their instructions suffers. This needs acceptance: digital inequality is a common phenomenon for everyone. There are differences in accessing and having the use of digital technologies today even in education.

In order to fill this gap, the researcher undertook a quantitative study to identify the inequalities in accessing the digital devices among the teachers of St. Aloysius Academy of Dasmariñas. In this manuscript, the researcher examines the inequalities, impact, challenges, and adherence to digital technology that impede, shape or mold teachers' trust and intuition towards digital technology in education.

\section{Review of Related Literature}

\subsection{What are Digital Devices?}

Bourgeois (2020) explains that digital device has the capacity to process electronic signals that represent either a one ("on") or a zero ("off The presence of an electronic signal represents the on-state while the off state is represented by the absence of an electronic signal. It is important to understand that each one or zero is referred to as a bit (a contraction of binary digit); a group of eight bits is a byte. It was noted that the first personal computers could process 8 bits of data at once; modern PCs can now process 64 bits of data at a time, which is where the term 64-bit processor comes from.

Bougeois emphasized that as the capacities of digital devices increased and new terms emerged to identify the capacities of processors, memory, and disk storage space. To represent different orders of magnitude, prefixes were applied to the word byte. Hence, these are digital specifications, the prefixes were originally meant to represent multiples of 1024 (which is 210), but have more recently been rounded to mean multiples of 1000.

Digital devices includes desktop computers, laptop computers, mobile phones, tablet computers, e-readers, storage devices, such as flash drives, input devices, such as keyboards, mice, and scanners and output devices such as printers and speakers. 


\subsection{Advantages of Using Digital Devices}

Rathore, et.al. (2019) claims that digital technology has transformed modern life that brought many advantages. This made possible for us to carry more computing and storage power in our mobile phones than was used to launch and land the first lunar module.

Digital Devices brought a higher level in every aspect of modern life which brough comfort as we deal with travel, work, shopping, entertainment, and communications . It is amazing to note that it's now rare to find an electronic device or piece of machinery that doesn't incorporate digital technology in some way.

As explained by Rathore, et.al., digital technology makes devices more compact, faster, lighter, and virtual. This expanded the scope of "information" which also included photos, audio, and video that has been digitalized. .

Digital Devices bring benefits to people as identified by Goodman (2020) which include, Social Connectivity, Communication Speeds, Versatile Working, Learning Opportunities, Automation, Information Storage, Editing, Accurate Duplication, GPS and Mapping, Transportation, Low Cost, Entertainment, News, Warfare. Banking and Finance and Smaller Sized Devices.

\subsection{Digital Inequalities}

Digital inequality researches seem focused on Internet access but dramatically included investigation on motivation, material access, skills, usage, and outcomes like Blank and Groselj, 2014 and Wei et al., 2011 making digital inequality research still heavily dependent on quantitative approaches and remains at a descriptive level.

Thus, it provides little explanatory power (Scheerder et al., 2017). Although these approaches help identify what segments of the population benefit most from the Internet, they do not explain why determinants result in beneficial Internet use. It is necessary to step back from the common quantitative approach used in digital divide research (Helsper, 2012; Mason and Hacker, 2003). Little empirical attention has been paid to social contextual factors, such as how the Internet is embedded in family life or how one's job stimulates (advanced) Internet use.

While digital divide research once started with a general focus on information and communication technologies (ICTs), in the past decades, it has mostly focused on the Internet.

\subsection{Digital Trust and Intuition}

Ritter (2020) defines digital trust as a level of confidence that people, technology and processes create a secure digital world. Digital trust is given to individuals and companies who have shown their users and subscribers capacities to provide safety, privacy, security, reliability, and data ethics with their online programs or devices. When a person decided to use a company's product or digital facilities they are actually giving their digital trust in the business.

Digital trust would mean dependability, helping the users to decide on a secure company that they will not find trouble in the future. It is a mutual trust between the users and the company that assures the user they will be receiving what they are asking for in a certain parameter of safe, secure and reliable manner. The more digital trust a company receives, the more successful they will become.

The stature of digital trust is stablished by both digital service companies and their consumers. Users apply digital trust to the search process for a service or device. Companies must envision for company-users symbiotic relationship which is digitally transformed in a high standard of security, safety, privacy and reliability .

On the other hand, as shared by This Week (2016), intuition seems a human skill just like an intuitive computer which acts according to its programming, but it also chooses what to do on the basis of something - knowledge, experience or a combination of the two - that its programmers cannot predict or fully explain. For digital intuition, Waks (2006) explains that the rich experience of teachers may guide them for their decision of taking opportunities to answer present challenges in the way that they decide without delay and maintain to generate educational value. When teachers are free from stresses and inevitable difficulties in their workplace, their work can exhibit intuition.

\section{Methodology}

This study was made possible through the use of a simple questionnaire prepared by the researcher. This study is quantitative in nature and the research design used was a descriptive method in order to describe the answer of the respondents. In terms of gathering the data, the researcher used simple random sampling as the sampling design. Due to the limitation of the study, the researcher selected 20 respondents from the teachers as a sample size of the population. 
A simple one-page questionnaire was used as the instrument for gathering the data. The researcher designed the survey questionnaire wherein teachers will just check their responses. The researcher will analyze and answers synonymic words for coding. The gathered data was tabled into frequency and percentage for easy presentation of data. Excel 2016 was the software used for the tabulation of the results.

\section{Results}

The results were based on the gathered data from the respondents. The gathered data were tabulated in order to present the data in a summary with a discussion to interpret the data presented.

\subsection{Digital Devices}

In Table 1, digital devices owned by the respondents are investigated. All of the respondents, $(100 \%)$ owns cellphones or smartphones, followed by $80 \%$ has a television at home and a laptop (75\%). Radio takes $50 \%$ followed by DVD Player of $35 \%$ while Tablet/pod takes $30 \%$. Being Desktop/PC and Digital Camera on the $7^{\text {th }}$ rank with $25 \%$ and the least is Printer and Scanner, $20 \%$ of the population. With this result, it can be established that the respondents are digitally inclined and have experienced using digital devices at home.

Table 1. List of Digital Devices owned by the Respondents.

\begin{tabular}{|c|c|c|}
\hline DIGITAL DEVICES & $\begin{array}{c}\text { FREQUENCY } \\
\mathbf{( N = 2 0}\end{array}$ & $\begin{array}{c}\text { PERCENTAGE } \\
(\mathbf{1 \% )}\end{array}$ \\
\hline Cellphones/Smartphone & 20 & 100 \\
\hline Laptop & 15 & 75 \\
\hline Desktop/PC & 5 & 25 \\
\hline Radio & 10 & 50 \\
\hline Printer and Scanner & 4 & 20 \\
\hline Television & 16 & 80 \\
\hline Digital Camera & 5 & 25 \\
\hline Tablet/Pod & 6 & 30 \\
\hline DVD Player & 7 & 35 \\
\hline Total & 88 & 100 \\
\hline
\end{tabular}

\subsection{Reasons for Using Digital Devices}

In the data presented in Table 2, most of the teacher-respondents disclosed that they use digital devices for academic purposes which is $30 \%$. While for access to information and communication, both got $25 \%$. Entertainment and convenience got $10 \%$.

Manifested to the responses of the teachers that they take advantage of the technology for their teaching profession. They use technology not only for their personal use but also for their job as teachers. This also evident their digital trust and intuition in teaching.

Table 2. Reasons for using the Digital Devices

\begin{tabular}{|c|c|c|}
\hline REASONS & $\begin{array}{c}\text { FREQUENCY } \\
(\mathbf{N = 2 0 )}\end{array}$ & $\begin{array}{c}\text { PERCENTAGE } \\
\text { (\%) }\end{array}$ \\
\hline For Entertainment/Leisure & 2 & 10 \\
\hline Academic Purposes & 6 & 30 \\
\hline Convenience & 2 & 10 \\
\hline Access to Information & 5 & 25 \\
\hline For Communication & 5 & 25 \\
\hline Total & 20 & 100 \\
\hline
\end{tabular}

\subsection{Frequency of Usage of the Digital Devices}

In the data presented in Table 4, most of the respondents which is $85 \%$ of the population use digital devices 5-6 hours a day, 2 of them consume 3-4 hours and 1 of the respondents use digital devices for 1-2 hours a day. This would mean that most of the teachers are digitally inclined as manifested of the 5-6 hours contact with digital devices. 
Table 3. Frequency of Usage of the Digital Devices.

\begin{tabular}{|c|c|c|}
\hline $\begin{array}{c}\text { Frequency of Usage of the Digital } \\
\text { Devices }\end{array}$ & $\begin{array}{c}\text { FREQUENCY } \\
(\mathbf{n = 2 0 )}\end{array}$ & $\begin{array}{c}\text { PERCENTAGE } \\
\text { (\%) }\end{array}$ \\
\hline Less than an hour/day1 & 0 & 0 \\
\hline 1-2 hours/day & 1 & 5 \\
\hline 3-4 hours/day & 2 & 10 \\
\hline 5-6 hours/day & 17 & 85 \\
\hline Total & 20 & \\
\hline
\end{tabular}

\subsection{Impact of Digital Devices}

The data on the impact of digital devices are presented in Table 4 . Most of the respondents with $25 \%$ considered Access to Information which takes a great impact on them for the use of digital devices. While for social interaction or socialize and Easy use for Communication take $20 \%$ of the population. Being Dependent on Digital Devices has the lowest impact which is $5 \%$. Social.

In terms of social, in this study this is under "For social interaction/socialize" and "Lessen social interaction" wherein got $20 \%$ and $10 \%$ respectively. Teachers are really social person and love social media. Despite busy work, they still find time to socialize not only to their students and parents but also with the community. Teachers' personality and brainpower are also developed by social media.

\section{Political}

Most of the teachers exposed themselves to political issues that they are interested to read news and information regarding politics and governance. They consider digital devices a great source for political information. Their decisions in life are affected by political affiliations.

\section{Economical}

When it comes to the economic aspect of the respondents this is being measured under the item "Makes life easy". Teachers find convenience using digital technology that of being manual to being technological. Of being teachers, manual labor makes their lives very toxic, but with the use of technology, they make being the teachers' lives easy. Digital device access transcends in making the lives in economic living. Looking into the overall digital divide economic access to digital technology, one can say that the gap between some relational groups of inequality is closing, though at different rates in different countries. Access to information affects their economic living.

\section{Cultural}

Culture is very much exposed in social media bringing changes on the culture itself but also became instrumental in preserving the culture. Teachers are vehicle in the preservation of our culture, thus they make use of the digital devices for this concern.

Table 4. Identified Impact of Digital Devices

\begin{tabular}{|c|c|c|}
\hline DESCRIPTION & $\begin{array}{c}\text { FREQUENCY } \\
(\mathrm{N}=20)\end{array}$ & $\begin{array}{c}\text { PERCENTAGE } \\
(\%)\end{array}$ \\
\hline Access to information & 5 & 25 \\
\hline For social interaction & 4 & 20 \\
\hline Easy use for communication & 4 & 10 \\
\hline Lessen social interaction & 2 & 5 \\
\hline Dependent on digital devices & 1 & 10 \\
\hline Makes life easy & 2 & 10 \\
\hline Influence decision making & 2 & \\
\hline Total & 20 & \\
\hline
\end{tabular}

\subsection{Challenges Encountered}

Fifty percent of the respondents answered "None". While "Influences Decision", "Cause of Misunderstanding, Miscommunication" and "Hard to Adopt Technologies got 10\%. Other challenges identified are presented in Table 6 . It can be inferred from the challenges encountered by teachers that they must be given more exposures and trainings about manipulation and facility of the digital technology. 
Table 5. Identified Challenges encountered using the Digital Device.

\begin{tabular}{|c|c|c|}
\hline CHALLENGES & $\begin{array}{c}\text { FREQUENCY } \\
(\mathbf{N = 2 0 )}\end{array}$ & $\begin{array}{c}\text { PERCENTAGE } \\
\text { (\%) }\end{array}$ \\
\hline None & 10 & 50 \\
\hline Influences Decision & 2 & 10 \\
\hline Cause of Misunderstanding & 2 & 10 \\
\hline Miscommunication & 2 & 10 \\
\hline Hard to adapt to new & 2 & 10 \\
\hline technologies & 1 & 5 \\
\hline Consumes time & 1 & 5 \\
\hline Addiction & 20 & 100 \\
\hline Total & & \\
\hline
\end{tabular}

\subsection{Adherence/Subscription to Digital Technology}

From the 20 identified digital technology devices and facilities, 100\% for the respondents are subscribing to smartphones, digital televisions, social media, computers, printers, self-scan machines, and ATM'S while 18 of them are reading websites. Eighty percent of the respondents is using digital cameras while 60 percent is using clocks and subscribing for bank and finances. Being robotics and drones as the lowest in $5 \%$. With these results, it can be concluded that teachers have established among themselves digital trust and intuition. They have been adhering and subscribing to various digital devices and facilities.

Table 6. Adherence/Subscription to Digital Technology

\begin{tabular}{|c|c|c|}
\hline DIGITAL TECHNOLOGY & $\begin{array}{l}\text { FREQUENCY } \\
(\mathrm{N}=20)\end{array}$ & $\begin{array}{c}\text { PERCENTAGE } \\
\text { (\%) }\end{array}$ \\
\hline Websites & 18 & 90 \\
\hline Buying and Selling Online & 5 & 25 \\
\hline Smartphones & 20 & 100 \\
\hline Digital Televisions & 20 & 100 \\
\hline Video Streaming & 10 & 50 \\
\hline eBooks & 5 & 25 \\
\hline Digital Music & 10 & 50 \\
\hline Geolocation & 4 & 20 \\
\hline Blogs & 4 & 20 \\
\hline Social Media & 20 & 100 \\
\hline Computers & 20 & 100 \\
\hline Printers & 20 & 100 \\
\hline Self-Scan Machines & 20 & 100 \\
\hline ATM'S & 20 & 100 \\
\hline Digital Cameras & 16 & 80 \\
\hline Cars and other Vehicles & 5 & 25 \\
\hline Clocks & 12 & 60 \\
\hline Robotics & 1 & 5 \\
\hline Drones & 1 & 5 \\
\hline Banking and Finances & 12 & 60 \\
\hline
\end{tabular}

\section{Conclusion}

The detrimental effect of COVID-19 pandemic not only to health and economy but to its challenges to education is something that cannot just be neglected by the teachers and the government. The continuation of education of the youth has to be championed under the new normal.

Teachers as agent and facilitator of information and knowledge must utilize digital technology in the delivery of distance education as a requirement of the new normal.

Access to digital devices is imperative to the lives of the teachers. Hence, the issues on digital inequality in the school must be addressed by the school managers and authorities by ensuring that all teachers have equal chances in accessing the digital technology-based teaching tools and by providing them skills in the manipulation of advanced technologies. 
The fact that teachers have been required to use computers for e-learning and for the submission and retrieval of records, they are compelled to subscribe with the digital trust and to make a decision of digitizing instructions. With this, teachers in the new normal must adhere with digital trust and intuition in order to assure the successful implementation of Schools Learning Continuity Plan (SLCP) as demanded by the new normal.

As the teachers overcome digital iniquities, they are ready to imbibe digital trust and intuition that would bring the parameter of digital education to a different level.

\section{Recommendations}

In conformity with the government mandates for no face to face education in the country, St. Aloysius Academy of Dasmariñas (SAAD) has been fully digitalized. In fact, for this school year enrollment and payment systems have been online. Graduation, meetings, and seminars were undertaken using various platforms on the internet.

SAAD is having continuous training for teachers about the creation of videos, podcast, and other digital learning materials. The school is also improving its infrastructure for online education. A Learning Management System (LMS) has been established which facilitates the administration, documentation, tracking, reporting, automation and delivery of educational courses, training programs, or learning and development programs.

As to the recommendation of this research, future studies must focus on the impact of Digital Technology to the teachers Psychologically, Socially, Politically, Economically and Culturally. It is also recommended to encourage school leaders to lobby with the government for the possible financial allocations to the students and teachers for the procurement of digital tools.

This research also recommends the capacitation the teachers on the use of the digital learning devices and develop among themselves digital trust and intuition that would assure full implementation of the Schools Learning Continuity Plans in time of Covid-19 Pandemic.

Funding: This research received no external funding.

Acknowledgments: The researcher would like to thank the teachers and administrators of the St. Aloysius Academy of Dasmarinas for their full cooperation and moral support in the conduct of this study. Special thanks to Romeo Christopher M. Avila for the statistical treatment and technical support.

Conflict of interest: The author declares no conflict of interest.

\section{References}

[1] Bourgeois, D. (2020). Information Systems Hardware Retrieved from https://eng.libretexts.org/Courses/Delta_College/CS_11Information_Systems_for_Business_(McClanahan)/02\%3A_Hardware

[2] [Digital Device. (n.d.). YOUR Dictionary Retrieved from https://www.yourdictionary.com/digital-device

[3] Digital Devices. (n.d.). Lumen Information Systems, Module 2 - Information System Hardware Retrieved from https://courses.lumenlearning.com/santaana-informationsystems/chapter/digital- devices/

[4] Editorial (n.n). (2016, Jan.). Digital Intuition. Nature, 529, 437 Retrieved from https://www.nature.com/news/polopoly_fs/1.19230!/menu/main/topColumns/topLeftColumn/pdf/529437a.pdf

[5] [Goodman, P. (2019, Jul 26). 16 Advantages of Digital Technolog, Turbo Future Retrieved from https://turbofuture.com/computers/Advantages-of-Digital-Technology

[6] Rouse M. (n.d.). Digital Trust. Whatls.com, TechTarget's IT encyclopedia Retrieved from https://whatis.techtarget.com/definition/digitaltrust\#: :text=Digital\%20trust\%20is\%20the\%20confidence,their\%20online\%20programs\%20or\%20devices.

[7] Scheerder, A. J., Van Deursen, A. J., \& van Dijk, J. A. (2019). Internet use in the home: Digital inequality from a domestication perspective. new media \& society, 21(10), 2099-2118. Retrieved from https://journals.sagepub.com/doi/full/10.1177/1461444819844299

[8] Svenson, Chaudhuri H, Das, A., Launer, M. (2020). Decision-making Style and Trusting Stance at the Workplace: A Socio-cultural Approach, (Pre-Print) Accepted Full Conference Paper, Gemeinschaften in Neuen Medien / Communities in New Media (GeNeMe'20), 7-9 October 2020, Dresden, Germany Retrieved from https://www.researchgate.net/publication/342638084_Decision-

[9] Teach with Digital Technologies. (n.d.) Victoria State Government, Education and Training Retrieved from https://www.education.vic.gov.au/school/teachers/teachingresources/digital/Pages/teach.aspx

[10] Tria J. (2020). The COVID-19 Pandemic through the Lens of Education in the Philippines: The New Normal. Research Gate Retrieved from https://www.researchgate.net/publication/341981898_The_COVID-

[11] Waks, L. J. (2006). Intuition in education: Teaching and learning without thinking. Philosophy of Education Archive, $379-388$.

[12] Yadav, P. (2019, May 8). What are the advantages of using digital devices?, Quora Retrieved from https://www.quora.com/What-arethe-advantages-of-using-digital-devices 